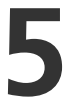

\title{
The Application of Norwegian Humane Ideals by Front-Line Workers When Collaboratively Reintegrating Inmates Back into Society
}

\section{William Dugdale and Sarah Hean}

\section{Introduction}

Traditionally, prison systems and their administrations have a strong focus upon the principles of punishment to ensure prisoners are effectively held accountable for their actions. This is balanced by the belief that prison may also serve as a site for rehabilitation (Maruna \& Immarigeon, 2004). The argument over the delivery of prisoner rehabilitation has been a long-standing issue within criminology: the What Works debate questions the effectiveness of this, exploring the methods used to address a prisoner's needs and thereby reduce rates of reoffending (McGuire, 1995; Ward \& Maruna, 2007). In order to successfully reduce

\footnotetext{
$\overline{\text { W. Dugdale }(\varangle) \cdot \text { S. Hean }}$

Bournemouth University, Bournemouth, UK

e-mail:wdugdale@bournemouth.ac.uk

S. Hean

University of Stavanger, Stavanger, Norway

e-mail: Sarah.c.hean@uis.no 
reoffending, empirical evidence has increasingly supported the view that rehabilitation and reintegration ought to be the prime focus for front-line staff working with inmates rather than merely punishment (Andrews \& Bonta, 2010).

In comparative criminology, Nordic countries, including Norway, are consistently portrayed as exceptions to the global move towards growing rates of imprisonment and tough on crime polices with less welfareorientation (Pratt, 2008a, 2008b). A balance of control versus rehabilitation is typified in the Norwegian prison system (Ugelvik, 2016), where policy aims to create conditions that seek to minimise prisoner deprivation, fear and suffering (Pratt \& Eriksson, 2011). The Norwegian prison system is widely regarded worldwide for its focus on prisoner treatment, rehabilitation and successful reintegration in the society with low reoffending rates of $20 \%$, in contrast with other European countries such as England and Wales that have a reoffending rate of $45 \%$ (Fazel \& Wolf, 2015; Pakes \& Holt, 2017). Although Norwegian prisons, the wellknown Halden and Bastøy for example, are said to refrain from inflicting further punishment upon prisoners, nevertheless, Jewkes (2020) calls for prison sociologists to subject prisons in Norway to rigorous empirical scrutiny.

Prisoner rehabilitation and reintegration requires careful interprofessional collaborative practice, provided by multiple key workers from different professional backgrounds and organisations (World Health Organization, 2010). Collaborative practice serves as an effective strategy to cope with the pressures within the prison environment and through group effort, improve the capacity for organisational personnel to work together (Bond \& Gittell, 2010; Wolff et al., 2013). Effective interprofessional collaboration generally is recognised as an active way of improving outcomes and the cost-effectiveness of care, but contributions are required from a range of professionals' competencies and skills across various services. Professionals, working with the complex care needs of a population and resource shortages, must therefore be able to work collaboratively in interprofessional teams/groups to mitigate challenges and ensure consistent, continuous, and reliable care (Bainbridge et al., 2010; WHO, 2010). It is also necessary to expand opportunities for innovation between these services. Studies on interprofessional practice 
enable an analysis of the drivers and barriers of collaboration with the practices among services being examined (Sørensen \& Torfing, 2011). Research has shown the importance of collaboration within prisons (Wolff et al., 2013) and Hean, Ødegård, et al. (2017), Hean, Willumsen, et al. (2017), Hean et al. (2018) have called for expanding knowledge on how this collaboration manifests and functions in this context. However, the processes of collaboration in this context are underexplored and requires field analysis of professional practice. There is a need for clarity in these collaboration processes across services as a mismatch in expectations creates unclear or disjoined working activity. Disparity can also blur the line of responsibility for resource provision. Research is therefore required to explore how services work collaboratively together.

This chapter explores interprofessional collaborative practice in the Norwegian prison context. It discusses findings from two immersive case studies (Yin, 2014) in eastern Norway, that explored specifically the perspectives of collaborative practices held by front-line professionals working in a particular Norwegian prison context, the transitional residence (overgangbolig). The chapter explores specifically one key issue that arose from this analysis, namely how the humane traditions that underpin the Norwegian prison system were manifested at the groundlevel by front-line professionals, promoting their collaborative practices while working together towards prisoner reintegration. It contributes to debate on how the foundational policies of differing European prison systems underpin front-line prison practice. We discuss how the contrasting punitive and rehabilitative/reintegrative ideals manifest, particularly in the daily work and interactions with each other and with prisoners. In other words, we explore how the humane traditions of the Norwegian system impact prison-based practices and the implications for front-line personnel and the collaborative nature of their work. 


\section{Humane Traditions in Norway}

Nordic countries are considered to maintain more humane prison regimes because of their distinctive welfare state models. In Norway, for example, this model is rooted in strong cultures of equality, social solidarity and cohesion (Pratt \& Eriksson, 2011). As a welfare state, the main goals of the Norwegian state is to give members of society the best possible conditions to maximise their own potential while remaining free to control him/herself and administer their own freedom (Foucault, 2007). Various services and front-line staff operationalise this goal of the welfare state when working together in prison on the common objective of rehabilitation and reintegration (Ugelvik, 2012, 2016; Smith \& Ugelvik, 2017).

Norwegian prison officer training and practice emphasises the humanistic side of the prison establishment (Bruhn et al., 2017) and organisational penal policy, such as the Norwegian government White Paper no. 37 (2008) Criminal punishment_Less crime-Safer society, outlines the key principles of security, rehabilitation, and reintegration. In this policy, rehabilitative and reintegrative work is considered central components of the prison sentence. It spells out explicitly that the professional practice within prisons is founded on a humanistic view that prisoners deserve equal treatment to that of the general population and that their debt to society has been paid once the sentence is completed. It takes the stance that reoffending rates may be reduced through the rehabilitation work of the Prison Service and that life within prison and out in community have to be as similar as possible. If the sentence is to work, the reintegration of a person must be planned and cared for in a good way to ensure the goal of a successful return to society is achieved. The humanist principles and values of the Norwegian prison system are also enforced in the Norwegian government White Paper no. 12 (2014) Development plan for capacity in the correctional care. The document recognises that prisoners should be seen as equal, have self-worth, be given choices and express creativity and that a convicted person must take responsibility for their own life and actions both during and after completion of a sentence. 
The values enshrined into the above documents, and in the Norwegian prison system overall, can be summarised by four key principles: the principles of justice, normality, progression, and proximity (Norwegian government White Paper no. 37, 2008). The principle of justice indicates that it is in fact the detention itself which is the punishment, thus the convicted person should not lose other civil rights. The principle of normality implies that a person's existence during a sentence shall be as equal as possible to life elsewhere in society, while the principle of progression is one that means during a sentence the conditions of confinement should gradually become less strict for a convicted person. This means the prisoner gains more freedom the closer the prisoner is to the completion of a sentence. Lastly, the principle of proximity indicates that convicted persons should be held in prisons as close to their home location as possible with the purpose to prevent social isolation and enable contact with family and the local community during their sentence. These humane principles written into the Norwegian penal policy direct professional practice in such a way to reduce the negative influences of a person's sentence (e.g. institutionalisation).

In operationalising these humane traditions, greater demands have been placed on prison service personnel to collaborate with outside health and welfare services to obtain proper housing, work, training, or other measures that can contribute to a lawful life for the inmates after release (Execution of Sentences Act, 2002; Kriminalomsorgen, 2005; Norwegian Ministry of Justice and Public Security, 2017). Supporting inmates in this way has been listed as a shared responsibility between agencies necessitating collaborative interprofessional relationships. The prison becomes part of a network of government agencies, volunteer organisations, and other services that together support change in the individual prisoner. Effective collaboration between all relevant bodies is essential if the rehabilitative and reintegration process is to be successful. The importance of cross-agency and management cooperation is recognised in the Norwegian penal code (Execution of Sentences Act, 2002), 
in the Kriminalomsorgen (2005) Occupational Guidelines for Correctional Care and manifested in the national educational curriculum of prison officers (Bruhn et al., 2017), cooperation agreements and joint instructions between agencies.

Despite the necessity for collaboration outlined above, the way collaborative practice may actually contribute or arise from the humane prison traditions and the link of this to the debated success of the Norwegian system are largely underexplored. This chapter therefore explores the impact of these traditions on prison practices and the implications for collaborative practice.

A focus on front-line staff is important first because of their close contact with the prisoner. At the front-line level, prison officers in their daily work are expected to guard, help, care for, and motivate those sent to prison, a fact that promotes a need for close collaboration to work with other service providers including health and welfare agencies (Smith \& Ugelvik, 2017). Front-line staff are also those individuals who in their occupational role implement the aims and policies of government. As such they dictate how the values and principles written in policy documents are implemented in the prison system (Bruhn et al., 2017). Fundamentally, front-line professionals are the crucial individuals, known by Lipsky (2010) as the street-level bureaucrats in public service employment, who perform their day-to-day work under certain structured conditions. These are the individuals who experience and undertake the critical roles that constitute the services recommended by the state. At the ground level, the public service workers interact directly with citizens in the course of their jobs with personal authority and discretion in how they deliver government policy. These front-line personnel have a considerable impact on people's lives. The work undertaken by front-line staff therefore mediates the relationship between citizens and the state (Lipsky, 2010), and their actions, including their collaborative actions, will ultimately dictate the effectiveness of prisoner rehabilitation and reintegration. 


\section{Transitional Residences}

In line with the principle of progression in the Norwegian prison system, prisoners move from a high or low security (open) prison to a half-way house, also referred to as a transitional residence, to serve the final part of their sentence before being released back into the community (Johnsen \& Fridhov, 2018). Known of as an Overgangsbolig, a transitional residence or half-way house is still a prison with clear control protocols. These prisons are typically perceived as less restrictive than other prisons with open conditions allowing inmates to have more freedom to attend work or education and live in the community as normally as possible. For an inmate to be transferred here it must be appropriate for the promotion of positive development and to reduce reoffending. Typically, an inmate has between three and eighteen months remaining of their prison sentence to be eligible to stay in the residence. The timeframe allows professionals an extended period to work with an inmate on their needs for living, work, and training. While residing at the prison, inmates must pay rent and agree to partake in either work or education outside the prison during the completion of their sentence. Through this process, collaboration with other services and professionals should take place to help rehabilitate inmates and plan for release and reintegration into society.

The transitional prison is a useful context in which to study collaborative practice because the provision of services at the transitional residence opposes the more commonplace service integration model, typically referred to as the Import Model, employed in prisons in Norway.

The Import Model was introduced into criminal justice policy and implemented in Norwegian prisons (Christie, 1970). It dictated that health and welfare services offered by the prisons are provided by the municipality in which the prison is located and not the prison itself (Bjørngaard et al., 2009). Ordinary authorities such as education and health services take responsibility for providing welfare and care in prison. Preceding this, services provided by doctors, nurses, and others were employed directly by the prison system. The intention of the Import Model is that by providing external health/welfare professionals, prison services are held to account by the external scrutiny of outside 
services and also that prisoners receive the same service as that provided by the general population.

In transitional prisons the Import Model falls away due to the freer conditions of the prisoners and the need to get prisoners more able to access external services for themselves in the community (Dugdale, 2020). Staff from other Norwegian prisons, health services such as the DPS (specialised psychiatric outpatient service) or NAV (the labour and welfare service) do not enter the transitional residences. Exploring collaborative practices in this context makes an interesting contrast to the study for collaborative practices elsewhere in Norway in high-security prisons (Hean, Ødegård, et al., 2017; Hean, Willumsen, et al., 2017) where the Import Model is in place. To develop collaborative working, there is a need to understand and assess organisational level effects of collaboration to further inform and innovate future practice and policy (Hean et al., 2011). Through examining organisational work, the key features of learning can be identified in work settings to promote and develop new forms of collaborative provision (Warmington et al., 2004). Cultural-Historical Activity Theory (CHAT) is considered particularly useful in this context by focusing on issues such as complex interactions, relationships, and their challenges to widen understanding of issues such as organisational learning, change, and collective knowledge creation (Engeström et al., 2007; Allen et al., 2011). In this penal context, CHAT is viewed as a constructive lens to theorise organisations through the activity systems model to identify the participants, their motivation, roles, and actions (Foot, 2014). As a theoretical framework, CHAT has been applied in organisational research to articulate the activity systems in which people collaborate the practical activities and their social origins (Blackler, 1993, 1995, 2009). This theoretical framework has been employed to gain an organisational view of collaborative practice as we consider the humane traditions and norms of the Norwegian prison system as a key mediating factor of professionals' ideals, and consequently the collaborative nature of their work.

Underpinning the research questions of this study (see Dugdale, 2020), CHAT has been used to analyse and describe the elements of organisational work being undertaken by the specific individuals of interest in the activity (Engeström, 1987, 1999, 2000, 2001). The core 
components of the activity system model, namely the object, tools, subject, community, rules, and division of labour, have been employed as analytical lenses to explore the interactions between these components and theorise the nature of collaboration practice. As the prime inquiry in this chapter, we consider the main findings from the subjects in this context to detail their agency and the applied ideals in the daily work with prisoners before they are released. The importance of the subjects' agency is that it is understood as the ability to construct and transform an individual's own work activity. An individual's agency is seen to depend not only on their own individual capabilities, but it is devised by other external factors such as the social norms of collaboration in the activity (Virkkunen, 2006). To account for the collaborative practices at the transitional residences in Norway, we have used CHAT to explore the link between the humane traditions/norms of this prison system which are clearly applied through the ideals of these front-line workers.

\section{Methods}

A case study approach (Yin, 2014) was employed as a form of inquiry and relied on multiple sources of data collection to collect rich and indepth descriptive data at two sites, namely the transitional residence. Immersive methods of data collection within prison-oriented research such as observations, shadowing, and semi-structured interviews. These were employed as they have proved to be important tools to build descriptive detail and uncovering the truth about the work undertaken within prisons (Liebling et al., 1999; Drake et al., 2015). To build an effective account of the prison system, a review of policy documentation released by the Norwegian government and the criminal justice system (Kriminalomsorgen) was conducted. This highlighted the key values and principles guiding staff.

Front-line professionals, such as prison officers, were a focus as they are the key individuals in undertaking daily prison practice. Employed by the Correctional Service, the purposeful sample of front-line staff were predominantly from a social work or prison-based background. The front-line professionals of the first case study encompassed six contact 
prison officers (equitable to prison officers in other European contexts), four social workers, and a nurse with pharmaceutical training to handle and manage the medication within the prison. The second case study incorporated six prison contact officers and five social workers.

The empirical data was collected through two months of immersive and observational fieldwork at each transitional residence, and specifically the front-line staff, including observations, shadowing a contact officer and social worker at each site, and semi-structured interviews with front-line staff. Observations and interviews were informed by the CHAT framework. Although data was collected on all dimensions of the activity system, we present specifically the findings that relate to the subjects' ideals.

As part of the fieldwork procedure, researchers participated and immersed themselves into the cultural web of the prison, becoming a part of it as much as possible. Similarly, the process was for the researcher to think, act, communicate, and feel as someone positioned in the web and needs to be emotionally, intellectually, and physically present (Ugelvik, 2014). To analyse the data, Template Analysis (King, 2004, 2012) was utilised as it has been demonstrated to be a clearly defined and flexible analytical method that refers to a group of techniques for thematically organising and analysing textual data. The key features which typify it are its flexibility of the coding structure, lack of prescription regarding levels of hierarchical coding, the use of a priori themes, and the iterative development and use of an initial template. A full description of the theoretical framework, empirical material, and iterative process of the analysis is presented elsewhere (see Dugdale, 2020).

Both case studies had 11 front-line professionals employed at each transitional residence, with space for 16 male and female inmates at the first case site, and 20 male inmates at the second. The prison leader and management were influential figures reinforcing the working principles at both prison sites and valuing the front-liners' autonomy, discretion, and input. Notably, the convicted persons at these prisons are formally considered inmates, yet both sets of professionals referred to them as clients or residents to reduce stigma and aid their transition back into community. To account for the sensitivity of the professionals' terminology in these findings, the term client will be referred to in place of 
inmate or prisoner. In both cases, each client was allocated one or two prison professionals as a contact officer to support their reintegration needs.

\section{Front-Line Reintegrative Practice}

The following section displays the centrality of front-line practice at the two prisons studied. The "objects" of the practices of staff observed here highlight the premise and key goals of the work undertaken by them at the two sites: the professionals' aim to socialise the clients and assist them access community-based services.

Referring firstly to socialisation, the clients had spent several years, and in some examples more than 10-15 years in prison. Therefore a prime aim of the professionals was to continue or begin the process of socially training the clients to live back in society. They did so through continuously re-evaluating and monitoring the prisoners' needs or lifestyle by becoming familiar with each client's routines, their problems, and daily happenings in their life. By working closely with each client, the staff ensured they were collectively familiar with the clients' well-being and their daily activities through regular interactions, such as informal conversations or one-to-one meetings. Similarly, these efforts were also about providing tailored one-to-one support based on the different needs and lifestyles of each client, required while living at the residence and planning for their return to the community (e.g. welfare including accommodation and finances, employment, education, physical, and mental health). Supportive relationships between offender/client and professional were therefore essential to develop openness and trust between the two parties. These relations were crucial to promote the clients' empowerment, reflect on the options available, and ensure the clients were taking primary responsibility for their daily activities. As a process, socialisation involved staff responding to the clients' needs, encouraging positive action or behaviour at the residence, and replicating a lifestyle that facilitated the prisoners' reintegration back into society. 
Recognising the second main object, the staff at these residences also ensured that the clients were accessing services which were based externally from the prison. The staff worked closely with each client to support access to the differing services in the community such as the welfare service NAV. However, it was primarily the responsibility of each client themselves to obtain the necessary specialised care or assistance in society as it would be a process they would be maintaining independently upon release. The staff distinguished between clients that were able to access services themselves, whereas others either did not have the knowledge or confidence to do so and therefore a professional would step up to assist such as making phone calls or attending appointments. We now consider the subjects at both transitional residences which articulated the professional ideals that underpin their daily tasks and were operationalised into practice.

\section{Professional Ideals}

\section{Case Study One}

At the first case study, the front-line professionals - the contact officers, social workers, and the nurse-had shared values of attempting to normalise the lives of clients. They provided a normal as possible structure for clients to aid their return to society and prevent them from returning to prison in the future. In pursing this, professionals envisaged themselves as motivational roles models:

that they believe in themselves, I try to make them believe in them self. To look at things easier. (contact officer one)

Each staff member wanted to do their best for the client as the longterm vision was to normalise their lives by having proactive routines such as having a job, educational course, or completing other domestic tasks. There was a collective consciousness with very little differentiation between the working ideals despite their contrasting educational/professional backgrounds. The focus was to be a person that the 
clients were able to look up to and be motivated by to change for the better. By actively reaching out, a professional would get to know each client's difficulties or flaws and attempt to influence positive behaviour or action. A key motivation for the professionals was that they wanted to work directly with people to provide "love and care" (social worker one) rather than excessively exerting punishment upon them while being in prison.

that we do our best to make, to help people become their best, becoming someone's neighbour, going back into society and you don't do that by punishing obviously but by helping in some way. (contact officer two)

Professionals viewed themselves as influential figures for the clients to live normally at the transitional residence and encourage a positive change for their future life in the community,

we also have better possibility to influence them, to maybe do some positive things for themselves. (contact officer three)

They articulated their work as being extremely meaningful as they were able to help individuals from difficult backgrounds to motivate and harness a meaningful life. The staff did not intend to harass or treat clients as if they were being watched, but to create a harmonious atmosphere that allowed the clients to live with increased autonomy to upkeep their own daily routines. Collectively, these outlooks emphasised the personable and responsive approach with each client rather than being overly controlling or exerting authority upon them. As part of daily life at the prison, the staff put humane treatment at the forefront of their work activity through manifesting a mutual respect and a sense of equality which built strong bonds between the staff and clients, "I think it's more of the personality and how we treat people" (nurse).

The professional work activity in the organisation was a balancing act of support and control at the prison. However, broadly speaking, security procedures and incidents were limited at the prison. It was seen as a time to build relations, interact and work closely with each client. Rather than being a restrictive place to live, the prison sentence itself was viewed as 
the punishment and professionals therefore wanted that clients get the most out of the remainder of their sentence. Professionals tried as much as possible to normalise the clients' lives, giving them peace of mind and tranquillity before shortly returning to society:

I mean the point is to normalise everything, you can't just have the prison thinking all the time, you have to get the other side too. (social worker two)

In summary, the ideals of the professionals at the first case study were collectively to normalise the clients' lives to motivate and support them while they progressed from finishing their prison sentence towards living back in the community. Although the normalisation principle in penal policy in Norway is strictly about normalising the services and living conditions in prison, here normalisation was about normalising the convicted persons' lives at the transitional residence.

\section{Case Study Two}

At the second case study, the professionals employed at the transitional residence were a balance of contact officers and social workers. The ideals of their work were one of reparation by wanting to repair the damage being in prison may have caused the clients. The collective outlooks of the staff was to give clients a second chance despite the crimes they had committed. The collective motivation was therefore to treat the clients respectfully and be impartial to the severity of their offences and give them an opportunity of a new life in the community:

Everyone deserves another chance. I think it's important, I also have in the back of my head I also think there is a reason for what everyone, everything happens for a reason. (contact officer two)

Staff spoke of not intending to judge them for their crimes as they wanted to treat them equally as normal citizens,

[Everyone] deserves respect as equal to yourself. (social worker one) 
A portion of the clients was known to have committed sex offences and the staff expressed a friendly approach to their work as they wanted to do their best for the clients and treat them equally regardless of the stigma associated with these crimes and sentences. The intentions were neither to judge nor to exert innocence or guilt upon the clients. Moreover, the collective emphasis was about working with people and their difficulties to offer a second chance of life and making amends for their mistakes,

I like working with people, I like to help people, I think that even the people who have done bad things they deserve a second chance. (social worker four)

Although several clients maintained their innocence, the intent of the workers were to be impartial and hear their thoughts rather than judge them for it, including critically discussing the position of the victim and maintaining an open thought process. The staff treated the clients respectfully as any other citizen to refrain from merely reading their sentence information and having a preconceived perception about an individual.

These key workers recognised the difficult and complex backgrounds of people in prison and acknowledged the narratives of each client and their complex upbringings or lives. The professionals had extensive experience in the prison system having worked with a wide range of clients serving sentences for murder, violence, drugs, and sex offences. Despite this, the time spent at the residence was an opportunity to offer clients a second chance in life to understand their perspectives and personal challenges. Similarly, recognition was also that the reason for being in prison did not necessarily have to malicious and the clients can still be supported to be good friends, fathers, and husbands.

the reason behind all of it doesn't need to be evil. It could be many reasons behind it, the reason doesn't need to be the most obvious reason. It would be something else that other people didn't think or didn't know about. (contact officer two) 
Comparatively to the first case, staff expressed the importance of balancing both security and support at the prison to ensure they always kept in mind the prison principles and supportive nature of their work,

we should have a nice balance of security and nice a balance of the good relationship we have. (contact officer one)

The front-liners reflected on their work experiences in other closed institutions and the importance of implementing some form of security at the residence, but that rehabilitation was the prominent focus,

It's mostly rehabilitation. Security, of course I have security in the back of my head because I worked 16 years in high security prison. (contact officer two)

Balancing these principles was to ensure that the clients have an element of structure or control, but also having supportive provisions to make amends for the extensive time in a closed prison and their own difficulties. The transitional residence was also seen as a place of tranquillity and harmony to focus on rehabilitation and the clients' ensuing reintegration, but still keeping in mind the security as this was an integral part of their education or work experience that upholds the safety of prison, staff, prisoners, and the public:

the social side is more important now I would say, but of course we have to always have in mind that we work in a prison and that's what I always say to my colleagues. (social worker one)

The professionals regularly reflected on their experiences at other institutions and the heightened focus on security. The increased control at closed establishments meant they were not able to spend extended periods of time alone with prisoners as it was not considered an essential or ordinary part of their work, along with always having staff safety in mind. The professionals now valued how they are able to have explicit focus on the supportive nature of their work at the transitional residence. Mutually, the ideals of the contact officers and social workers at this second case were to support the clients to make amends for their 
mistakes, foster their own personal development, and progress towards a life back in society.

\section{Discussion}

Beginning this discussion, these findings demonstrate the compatibility and application of the professionals' humane ideals across the two transitional residences in Norway that were translated into practice. Earlier in this chapter we presented the humane traditions/norms of the prison system that have been encapsulated into the policy and training. Thus, we consider the link between the humane traditions/norms in Norway that have been expressed in the ideals at each case study site to discuss how these ideals manifest the collaborative practices that were observed.

In line with Lipsky (2010), we have viewed how government policy is played out at the front-line in which the diverse occupations of public service personnel may entail improvisation and responsiveness to individual cases, but they are said to be embodied by an essential paradox that is highly scripted to perform and achieve relatively clear objectives derived from the political culture. Irrespective of the differing professions at the two prison sites, the application of these professional ideals reframed from having fragmented or separated service personnel. Thus, the shared welfare-orientated and humane outlooks encouraged the multi-voiced professionals at each transitional residence to reintegrate inmates back into society. In CHAT terms, the mediation between the traditions/norms of the prison system and the key front-line subjects play an important role in shaping and informing the work activity based on the origin of the subjects' social needs. This holds importance as the subjects' motivation can evolve and is viewed as a directed action towards the emerging priorities and objects (action and goals) of the activity (Miettinen, 2005).

Prisons in Norway are said to belong to a humane tradition and culture with an underpinning value of penal welfare, together with a long reputation and tradition for pursuing humanistic prison policies that embrace rehabilitation within prisons (Pratt \& Eriksson, 2013). As front-line professionals are considered the key individuals who transform the aims and policies of the government and the prison system 
into practice (Bruhn et al. 2017), greater demands have been placed on the Correctional Service and the ideals of front-line personnel in prisons to work collaboratively. This position reflects the traditions in the Norwegian penal code to implement agreements and joint instructions to contribute towards co-creating effective positive solutions for inmates before, during, and after a sentence. These traditions illuminate the fundamental values of the prison system and the growth of collaboration between prison staff to refrain from merely punishing inmates (Execution of Sentences Act, 2002; Kriminalomsorgen, 2005). In this case, the emerging ideals at the front-line are viewed as key contributors that mediated collaborative practice at the transitional residences.

Transforming the government policies into practice is seen to not only mediate the emerging ideals of public service personnel, but also has implications for collaborative practice. As prison systems are said to amalgamate working cultures into their penal policies, local variations in the interpretation and implementation of practice can still occur possibly due to the wide array of organisations and complex working environment in prisons (Rudes \& Magnuson, 2019). The work undertaken in prisons can represent challenges due to conflicting ideals to punish convicted persons, protect citizens from criminals, and rehabilitate prisoners to ensure that they desist from committing further crime upon release from prison (Griffin, 2002). The effectiveness of prisons can be inhibited by administrations that overtly focus on other punitive measures such as control. It is argued that the punitive philosophy of prison work has a detrimental effect on the performance of the organisational goals of staff within prisons. Strategies that are heavily autocratic can also undermine the social cohesion and rehabilitative work undertaken by staff in prisons (Craig, 2004). Explicitly, empirical studies in criminology and sociology have therefore increasingly supported the philosophy of rehabilitating inmates rather than merely punishing them to reduce reoffending (Ward \& Maruna, 2007). As seen in these two case studies, the underpinning policies of a system can play an important part in facilitating and supporting front-line staff to manifest common outlooks while working with inmates. Consequently, the underpinning traditions/norms of the Norwegian prison system informed the professionals' shared ideals, which in turn, stimulated collaborative practice among the workforces. 
Bruhn et al. (2017) discuss the daily regimes that involve interactions 24 hours a day with prisoners while constantly guarding, helping, caring, and motivating those sent to prison, the dilemmas of prison work therefore stem from the need to find a balance between security procedures and rehabilitative work in everyday practice. The ongoing occupational development and professionalisation of prison officers is said to run consistent with the central aims of Norwegian prison policy, developing the humanistic side of the prison establishment with a focus on openness, respect, and professionalism. The development of prison staff has also been structured around different interprofessional fields such as security and safety, social work and reintegration rather than merely traditional security disciplines, outlining the goal of having well-developed collaborative relationship between prison officers, other staff, and prisoners. In Norway, humanistic prison policy and training have changed a prison officers' role from simply a guard role to one which encompasses the motivation and rehabilitation of prisoners (Bruhn et al., 2017). The professional development of prison staff is important as poor quality and inexperienced workforce with problematic training undermines the safety and well-being or prisoners and staff (Crewe et al., 2011). Frontline prison staff in Norway are expected to guard, help, care for and motivate those sent to prison, a fact that promotes close collaboration to work with other professional colleagues (Smith \& Ugelvik, 2017).

Differentiating between the official tasks listed in policy and training (the job description of prison staff), and the activity (what staff actually undertake), the staff at the overgangsbolig centralise the collaborative rehabilitative and reintegrative work with prisoners, rather than disproportionately employing their authority or security measures. At the heart of prison life, the professionalism of staff is seen as critical for authority to be used legitimately and being good at not using force, but to still be in control and things still getting done (Liebling, 2011). High levels of staff professionalism which are a matter of craft, skill, and fairness, are necessary to assure high-quality services that reflect an organised and professionalised ethos (Crewe et al., 2015). The professionalism is viewed as key to determine the quality of prison life as it mediates the attitudes of prison staff and their ability to initiate routines that are fair, safe, respectful, reliable, and responsive (Rynne et al., 2008). Staff 
that value the peaceful coexistence with prisoners evoke mutual respect, human dignity, sharing of resources, and the development of individual potential (Crewe \& Liebling, 2012). The professionalism in Norway is an important consideration that evoked the collaborative attitudes at the overgangsbolig. Similarly, these humanistic ideals are said to reinforce the idea that smaller prisons in Norway demonstrate a collaborative ethos between not only other staff, but also prisoners for prison life to run smoothly (Johnsen \& Granheim, 2012). Opposed to having differing professional outlooks, these ideals as seen as important to be operationalised collaboratively into practice while working with prisoners prior to release.

To problematise these findings, there is little consideration for prisoners who have an increased level of need and require more specialised support. Dilemmas may be present at these sites as the staff view prisoners idealistically and there may be less opportunities for these individuals characterised as excessively "needy" to reside at these prisons. Prioritising persons who already hold a certain level of capabilities to live in the community may be considered beneficial here, but individuals that have experienced extensive institutionalisation require further attention (see Wolff et al., 2012). Moreover, individuals' encountering an increasing level of need resemble a challenge for staff at the reintegrative phase of a prison sentence to effectively transition them from prison to society.

To reiterate the key argument, the traditions in Norway has positioned professionals in prisons to have a humanistic view of prisoners deserving equal treatment to that of the general population, self-worth, creativity, and that convicted persons have made up for the penalty of a crime once the sentence is completed. Reoffending rates should be reduced through the rehabilitation and reintegrative work of the Correctional Service with life within prison and out in community having as little difference as possible to ease reintegration. A rehabilitative and reintegrative emphasis are considered central components of the prison sentence and if the sentence is to work, the reintegration of an inmate must be planned and cared for in a good way to ensure that the goal of successfully returning to society is achieved. Recognition is that individuals have 
the right to make their own choices and take responsibility for the consequences of the actions taken during their prison sentence. A convicted person must therefore have empowerment in their own life, both during and after completion of a sentence to ease the transition from prison to the community.

In Norway, the underpinning penal policies have aimed to uphold traditions that direct staff and promote redemption, learning, training, healing, and the commitment to normalisation in prisons (Pratt \& Eriksson, 2011). Compared to the rehabilitation and reintegrative strategies of other countries, the Norwegian approach is deemed to be a good one as many prisoners receive the help to manage and establish a life without crime (Johnsen \& Fridhov, 2018). Suggestions from this study are that the underpinning humane traditions which focus on the welfare of inmates such as their rehabilitation and reintegration took precedence over other principles such as punishment at the transitional residences. These traditions are considered important for practice to reinforce the shared ideals across the multidisciplinary personnel and to conduct collaborative practice as they reintegrate inmates back into society.

While expanding knowledge at the front-line of the Norwegian prison system, the key message demonstrates the underpinning traditions of penal policy and the link between how these are operationalised and collaboratively translated into practice through the shared ideals of frontline staff. Indications are that there is compatibility between the humane traditions that underpin the prison system, and the ideals applied by the front-line professionals. The shared humane ideals were found to stimulate collaborative practice among the staff while working with inmates' needs before they were released from the transitional residences and to reintegrate them back into society. Recommendations are for future research across European prison systems to expand knowledge of the contrasting traditions that underpin systems/policies and the implications upon prison administrations, institutions, front-line staff, and across the progressive phases of a convicted person's sentence. These traditions are considered influential to reinforce the conceptions of frontline staff that guide the collaborative practices in prisons. Evaluating current educational and training programmes of front-line staff, most 
notably prison officers and other service personnel in prisons is also a key consideration. Understanding the current education of prison-based staff is seen as critical to map the needs, obstacles, and challenges of different personnel, which in turn provides an opportunity to inform future interprofessional education and develop collaborative practice that effectively reduces reoffending.

\section{Conclusion}

Through expanding knowledge of organisational prison policy and practice in the Norwegian prison system, the research demonstrates the humane traditions that underpin this system and were applied by frontline personnel at two transitional residences. Irrespective of the differing professions at these sites, the shared humane ideals of front-line staff suggest that a welfare embedded approach prioritising rehabilitation and reintegration take precedence over punishment in the final stages of an inmate's sentence. These ideals are noteworthy if contrasting principles and values are at odds with each other and may have implications for collaborative practice to occur across professions. Rather than creating division and disparity between different professional groups, the Norwegian prison staff outlined their common ideological capacity to encourage working as a collaborative workforce at the two transitional residences. Consequently, this study finds that there seems to be compatibility between the humane traditions that underpin the Norwegian prison system and the shared ideals applied within front-line practice. These ideals are noteworthy at the final phase of the prison system to encourage collaborative practice among front-line professionals to reintegrate inmates back into society. 


\section{References}

Allen, D. K., Karanasios, S., \& Slavova, M. (2011). Working with activity theory: Context, technology, and information behavior. Journal of the Association for Information Science and Technology, 62(4), 776-788.

Andrews, D. A., \& Bonta, J. (2010). Rehabilitating criminal justice policy and practice. Psychology, Public Policy, and Law, 16(1), 39-55.

Bainbridge, L., Nasmith, L., Orchard, C., \& Wood, V. (2010). Competencies for interprofessional collaboration. Journal of Physical Therapy Education, $24(1), 6-11$.

Bjørngaard, J. H., Rustad, A. B., \& Kjelsberg, E. (2009). The prisoner as patient-A health services satisfaction survey. BMC Health Services Research, 9(176), 1-9.

Blackler, F. (1993). Knowledge and the theory of organizations: Organizations as activity systems and the reframing of management. Journal of Management Studies, 30(6), 863-884.

Blackler, F. (1995). Knowledge, knowledge work and organizations: An overview and interpretation. Organization Studies, 16(6), 1021-1046.

Blackler, F. (2009). Cultural-historical activity theory and organization studies. In A. L. Sannino., H. Daniels., \& K. D. Gutierrez (Eds.), Learning and expanding with activity theory (pp. 19-39). New York: Cambridge University Press.

Bond, B. J., \& Gittell, J. H. (2010). Cross-agency coordination of offender reentry: Testing collaboration outcomes. Journal of Criminal Justice, 38(2), $118-129$.

Bruhn, A., Nylander, P. Å., \& Johnsen, B. (2017). From prison guards to... what? Occupational development of prison officers in Sweden and Norway. Journal of Scandinavian Studies in Criminology and Crime Prevention, 18(1), 68-83.

Christie, N. (1970). Modeller for en fengselorganisasjon. In R. Østensen (Ed.), I stedet for fengsel. Oslo: Pax Forlag.

Craig, S. (2004). Rehabilitation versus control: An organizational theory of prison management. Prison Journal, 84(4), 92-114.

Crewe, B., \& Liebling, A. (2012). Are liberal-humanitarian penal values and practices exceptional? In T. Ugelvik, \& J. Dullum (Eds.), Penal exceptionalism? Nordic prison policy and practice (pp. 175-198). London: Routledge. 
Crewe, B., Liebling, A., \& Hulley, S. (2011). Staff culture, use of authority and prisoner quality of life in public and private sector prisons. Australian \& New Zealand Journal of Criminology, 44(1), 94-115.

Crewe, B., Liebling, A., \& Hulley, S. (2015). Staff-prisoner relationships, staff professionalism, and the use of authority in public- and private-sector prisons. Law \& Social Inquiry, 40(2), 309-344.

Drake, D. H., Earle, R., \& Sloan, J. (2015). General introduction: What ethnography tells us about prisons and what prisons tell us about ethnography. In D. H. Drake, R. Earle, \& J. Sloan (Eds.), Palgrave handbook of prison ethnography (pp. 1-16). Basingstoke: Palgrave Mcmillan.

Dugdale, W. (2020). Interprofessional collaborative practice in the Norwegian prison system: A case study exploration of front-line professionals at two transitional residences reintegrating inmates back into society (Published doctoral thesis). Bournemouth, UK: Bournemouth University.

Engeström, Y. (1987). Learning by expanding. Helsinki: Orienta-Konsultit Oy. Engeström, Y. (1999). Activity theory and individual and social transformation. In Y. Engeström., R. Miettinen., \& R. L. Punamäki (Eds.), Perspectives on activity theory (pp. 19-38). Cambridge: University Press.

Engeström, Y. (2000). Activity theory as a framework for analyzing and redesigning. Ergonomics, 43(7), 960-974.

Engeström, Y. (2001). Expansive learning at work: Toward an activity theoretical reconceptualization. Journal of Education and Work, 14(1), 133-156.

Engeström, Y., Kerosuo, H., \& Kajamaa, A. (2007). Beyond discontinuity: Expansive organizational learning remembered. Management Learning, 38(3), 319-336.

Fazel, S., \& Wolf, A. (2015). A systematic review of criminal recidivism rates worldwide: Current difficulties and recommendations for best practice. PLoS ONE, 10(6), 1-8.

Foot, K. A. (2014). Cultural-historical activity theory: Exploring a theory to inform practice and research. Journal of Human Behavior in the Social Environment, 24(3), 329-347.

Foucault, M. (2007). Security, territory, population. New York: Palgrave Macmillan.

Griffin, M. L. (2002). The influence of professional orientation on detention officers' attitudes toward the use of force. Criminal Justice and Behavior, 29(3), 250-277.

Hean, S., Heaslip, V., Warr, J., \& Staddon, S. (2011). Exploring the potential for joint training between legal professionals in the criminal justice system and health and social care professionals in the mental-health services. Journal of Interprofessional Care, 25(3), 196-202. 
Hean, S., Ødegård, A., \& Willumsen, E. (2017). Improving collaboration between professionals supporting mentally ill offenders. International Journal of Prisoner Health, 13(2), 91-104.

Hean, S., Willumsen, E., \& Ødegård, A. (2017). Collaborative practices between correctional and mental health services in Norway: Expanding the roles and responsibility competence domain. Journal of Interprofessional Care, 31(1), 18-27.

Hean, S., Willumsen, E., \& Ødegård, A. (2018). Making sense of interactions between mental health and criminal justice services: the utility of cultural historical activity systems theory. International Journal of Prisoner Health, 14(2), 124-141.

Jewkes, Y. (2020). "An Iron Fist in a Silk Glove”: The pains of Halden Prison. In B. Crewe, A. Goldsmith, \& M. Halsey (Eds.), Power and authority in the modern prison: Revisiting the society of captives. Oxford: Clarendon Press.

Johnsen, B., \& Fridhov, I. M. (2018). Offender resettlement in Norway: Positive principles-Challenging practices. In F. Dünkel, I. Pruin, A. Storgaard, \& J. Weber (Eds.), Prisoner resettlement in Europe (pp. 249-262). London: Routledge.

Johnsen, B., \& Granheim, P. K. (2012). Prison size and quality of life in Norwegian closed prisons in late modernity. In T. Ugelvik, \& J. Dullum (Eds.), Penal exceptionalism? Nordic prison policy and practice (pp. 199-214). London: Routledge.

King, N. (2004). Using templates in the thematic analysis of text. In C. Cassell \& G. Symon (Eds.), Essential guide to qualitative methods in organizational research (pp. 256-270). London: Sage.

King, N. (2012). Doing template analysis. In G. Symon, \& C. Cassell (Eds.), Qualitative organizational research: Core methods and current challenges. (pp. 426-450). London: Sage.

Kriminalomsorgen. (2005). Yrkesetiske retningslinjer for kriminalomsorgen (Occupational guidelines for the correctional care) (2nd ed.). Oslo: Kriminalomsorgens sentrale forvaltning.

Liebling, A. (2011). Distinctions and distinctiveness in the work of prison officers: Legitimacy and authority revisited. European Journal of Criminology, $8(6), 484-499$.

Liebling, A., Elliot, C., \& Price, D. (1999). Appreciative inquiry and relationships in prisons. Punishment \& Society, 1(1), 71-98.

Lipsky, M. (2010). Street-level bureaucracy: Dilemmas of the individual in public service (30th Ann ed.). New York: Russell Sage Foundation. 
Maruna, S., \& Immarigeon, R. (2004). After crime and punishment: Pathways to offender reintegration. Cullompton: Willan Publishing.

McGuire, J. (1995). What works: Reducing reoffending. Guidelines from research and practice. Chichester: John Wiley \& Sons Ltd.

Miettinen, R. (2005). Object of activity and individual motivation. Mind, Culture, and Activity, 12(1), 52-69.

Norwegian Government White Paper no. 12 (2014). Utviklingsplan for kapasitet I kriminalomsorgen (Development plan for capacity in the correctional care). Oslo: Departementenes sikkerhets- og serviceorganisasjon.

Norwegian Government White Paper no. 37 (2008). Straff som virker - mindre kriminalitet - tryggere samfunn (Criminal punishment_Less crime-Safer society). Oslo: Departementenes servicesenter.

Norwegian Ministry of Justice and Public Security. The Execution of Sentences Act 2002.

Norwegian Ministry of Justice and Public Security. (2017). Redusert tilbakefall til ny kriminalitet: Nasjonal strategi for samordnet tilbakeforing etter gjennomfort straff 2017-2021. Oslo: Justis- og beredskapsdepartementet.

Pakes, F., \& Holt, K. (2017). Crimmigration and the prison: Comparing trends in prison policy and practice in England \& Wales and Norway. European Journal of Criminology, 14(1), 63-77.

Pratt, J. (2008a). Scandinavian exceptionalism in an era of penal excess: Part I: The nature and roots of Scandinavian Exceptionalism. British Journal of Criminology, 48(2), 119-137.

Pratt, J. (2008b). Scandinavian exceptionalism in an era of penal excess: Part II: Does Scandinavian exceptionalism have a future? British Journal of Criminology, 48(3), 275-292.

Pratt, J., \& Eriksson, A. (2011). "Mr. Larsson is walking out again”. The origins and development of Scandinavian prison systems. Australian \& New Zealand Journal of Criminology, 44(1), 7-23.

Pratt, J., \& Eriksson, A. (2013). Contrasts in punishment: An explanation of Anglophone excess and Nordic exceptionalism. London: Routledge.

Rudes, D. S., \& Magnuson, S. (2019). Scapegoating culture: Misunderstanding organizational culture as the problem in carceral institutions and beyond. Sociology Compass, 13(2), 1-12.

Rynne, J., Harding, R., \& Wortley, R. (2008). Market testing and prison riots: How public-sector commercialization contributed to a prison riot. Criminology and Public Policy, 7(1), 117-142.

Smith, P. S., \& Ugelvik, T. (2017). Scandinavian penal history, culture and prison practice: Embraced by the welfare state? London: Palgrave Macmillan. 
Sørensen, E., \& Torfing, J. (2011). Enhancing collaborative innovation in the public sector. Administration \& Society, 43(8), 842-868.

Ugelvik, T. (2012). The dark side of a culture of equality: Reimagining communities in a Norwegian remand prison. In T. Ugelvik \& J. Dullum (Eds.), Penal exceptionalism? Nordic prison policy and practice (pp. 121-138). London: Routledge.

Ugelvik, T. (2014). Prison ethnography as lived experience: Notes from the diaries of a beginner let loose in Oslo Prison. Qualitative Inquiry, 20(4), 471-480.

Ugelvik, T. (2016). Prisons as welfare institutions? Punishment and the Nordic model. In J. Bennett, Y. Jewkes, \& B. Crewe (Eds.), Handbook on prisons (pp. 388-402). London: Routledge.

Virkkunen, J. (2006). Hybrid agency in co-configuration work. Outlines. Critical Practice Studies, 8(1), 61-75.

Ward, T., \& Maruna, S. (2007). Rehabilitation: Beyond the risk paradigm. London: Routledge.

Warmington, P., Daniels, H., Edwards, A., Brown, S., Leadbetter, J., Martin, D., et al. (2004). Interagency Collaboration: A review of the literature. Bath: Learning in and for Interagency Working Project.

Wolff, N., Frueh, B. C., Huening, J., Shi, J., Epperson, M. W., Morgan, R., et al. (2013). Practice informs the next generation of behavioral health and criminal justice interventions. International Journal of Law and Psychiatry, 36(1), 1-10.

Wolff, N., Shi, J., \& Schumann, B. E. (2012). Reentry preparedness among soon-to-be-released inmates and the role of time served. Journal of Criminal Justice, 40(5), 379-385.

World Health Organization. (2010). Framework for action on interprofessional education \& collaborative practice. Geneva: Health Professions Network Nursing and Midwifery Office.

Yin, R. K. (2014). Case study research: Design and methods (5th ed.). Los Angeles: Sage. 
Open Access This chapter is licensed under the terms of the Creative Commons Attribution 4.0 International License (http://creativecommons.org/ licenses/by/4.0/), which permits use, sharing, adaptation, distribution and reproduction in any medium or format, as long as you give appropriate credit to the original author(s) and the source, provide a link to the Creative Commons license and indicate if changes were made.

The images or other third party material in this chapter are included in the chapter's Creative Commons license, unless indicated otherwise in a credit line to the material. If material is not included in the chapter's Creative Commons license and your intended use is not permitted by statutory regulation or exceeds the permitted use, you will need to obtain permission directly from the copyright holder.

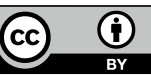

